\title{
A Comparative Analysis of User Preferences for Four Major Internet Based Education Media in China
}

\author{
Chunyang Wan \& Yanqing Jiang \\ School of Economics and Finance, Shanghai International Studies University, Shanghai, P. R. China \\ Correspondence: Yanqing Jiang, School of Economics and Finance, Shanghai International Studies University, No. \\ 1550 Wenxiang Rd., Shanghai 201620, P. R. China
}

Received: June 19, 2014

Accepted: June 23, $2013 \quad$ Online Published: July 3, 2014

doi:10.11114/jets.v2i3.447

URL: http://dx.doi.org/10.11114/jets.v2i3.447

\begin{abstract}
Internet based education media are developing at an amazing rate and being seen as an upstart that is likely to dominate traditional education means worldwide in the future. This paper presents and discusses empirical results of a comparative analysis of user preferences for four major types of internet-based education media being used in China. In this paper, we first sort the currently prevalent internet-based education media in China into four basic types and summarize their different characteristics. We then categorize the users by a two-step procedure of clustering analysis, based on which we finally figure out the preference of each user cluster and identify the major influencing factors.
\end{abstract}

Keywords: comparative analysis, internet-based education media, two-step clustering

\section{Introduction}

Wide access of education to the public by using effective information technologies is one aspect of the successes of today's society (Colwell, 2001; Starke-Meyerring and Andrews, 2006). As the whole world steps into the big data era, the use of internet-based means in education has become increasingly significant. Different types of internet-based education media have been developed and the number is growing at an amazing rate. Internet-based media provide the promise of increased access to high quality education for the public ((Bates, 2003; Moore and Anderson, 2003). Apart from some world-renowned online education platforms such as MOOC (Massive Online Open Courses) and the long-existing online education communities, multiple other internet-based education media have been developed in China and are being widely used by users of various backgrounds.

The evolution of the modern world economy calls urgently for a well-educated workforce (Dykman and Davis, 2008). For example, the three I's (India, Indonesia, and Ireland) and more recently China, are finding that the demand for an educated workforce is overwhelming the capacities of their traditional educational systems (Brown, Murphy, and Wade, 2006; Chen, 2007; Jacob and Szirmai, 2007; Tilak, 2007; Dykman and Davis, 2008). Seeing the growing importance of internet-based education, especially in the context of developing countries, in the current study we implement a comparative analysis of user preferences for different internet-based education media in China and identify their influencing factors. The results may well be used by developers of those media in making improvements related to their products and services, or by designers who are currently engaged in finding niches in developing new ways of online education.

The rest of this paper is organized as follows. Section 2 is devoted to a literature review. In Section 3, we present a brief introduction to the methodology being applied to the comparative analysis in this paper. In Section 4, which is the main body of the current study, we describe our research procedure, present our findings, and hold related discussions on the important issues. Section 5 presents the final results of our comparative analysis. Finally, Section 6 concludes our analysis by summarizing and highlighting our research findings in this paper.

\section{Literature Review}

While very few literature directly related to online education media is available, certain preference analyses using similar methods on other subjects give abundant inspirations to this paper, especially in terms of the methodology. Undoubtedly, the principles of preference analysis and clustering method themselves play a crucial role in guiding the analyzing process. Wended Smith (1956) put forward the theory of market segmentation, which pointed out that customers can be sorted into different groups according to their different culture recognitions, level of income, and 
consuming habits. Only through targeting different customer groups and providing them with customized products and services can firms efficiently compete over others using limited resources. Therefore in this paper, when doing preference analysis, we do not merely lump feedbacks from different users indiscriminately. Instead, we conduct a two-step clustering analysis that groups those users into different types. Clustering analysis is an ideal statistical technique which deals with multiple variables. Several types of clustering method are being used in numbers of research fields, among which the most frequently used is recognized as the hierarchical clustering, which is virtually a kind of connectivity model based on distance connectivity. Then there comes the K-means algorithm as well as its improved versions like the K-prototype and $\mathrm{K}$-mode algorithms. These clustering algorithms represent each cluster by a single mean vector. Others include density models (DBSCAN and OPTICS), group models, subspace models and graph based models. The two-step clustering algorithm is a special tool primarily used when dealing with mixed variables which include both continuous and discrete variables. It is a featured tool belonging to hierarchical clustering.

With respect to the customer clustering analysis, preference analysis and online education media studies per se (not necessarily involving the use of the two-step clustering method), there are several prior studies from which we get inspirations. Lu (2012) applies K-means clustering in management of customer relationship in the telecommunicating industry and brings forward several enlightening suggestions in terms of maintaining firms' competence in optimizing customer relationship. Liu, Wang, Liu, and Zhong (2005) use a clustering-based method on mining text preference: the experience results indicate that this clustering-based method can present user text preference more precisely while it is not sensitive to relevance threshold. Regarding online education media, we basically review some literature concerning features of certain online education means since few preference analyses have been conducted in this field. Wang, Zhang, and Zhang (2013) choose seven different MOOC programs abroad as the samples and figure out the MOOC characteristics in terms of organizing mechanics, positioning, courses organizing, resources, teaching methods and quality accreditation, and put forward suggestions in developing the Chinese MOOC market based on their findings. Chen and Wang (2013) compare features of MOOC and traditional education means, and argue that key features of MOOC can be summarized as large-scaled, highly open, internationalized and innovative.

We may notice that the literature mentioned above primarily focuses on a specific field, either in the application of the clustering method or the preference analysis, or in learning about a certain type of online education means. Up to now, there exists no synthesized analysis that, by linking all the related fields together, presents more comprehensive and accurate empirical results regarding the preferences of online education platform users. This paper aims to fill out the blank page and expand the current research scope by providing a thorough comparative analysis of four internet-based education means currently being widely used in China.

\section{Methodology}

We start by designing a questionnaire, which is later distributed to respondents in order to obtain a random sample of current or potential users of online education platforms. In this questionnaire, we present details of different characteristics of the four different types of online education media that are currently being widely used in China. Each respondent (seen as a current or potential user of online education) is expected to provide a subjective assessment for each type of the media by answering the questions and giving scores to those media. Based on the feedbacks of the respondents, we sort these users using a clustering analysis and then figure out their preferences and the influencing factors of each user cluster. The research framework can be portrayed in Figure 1.

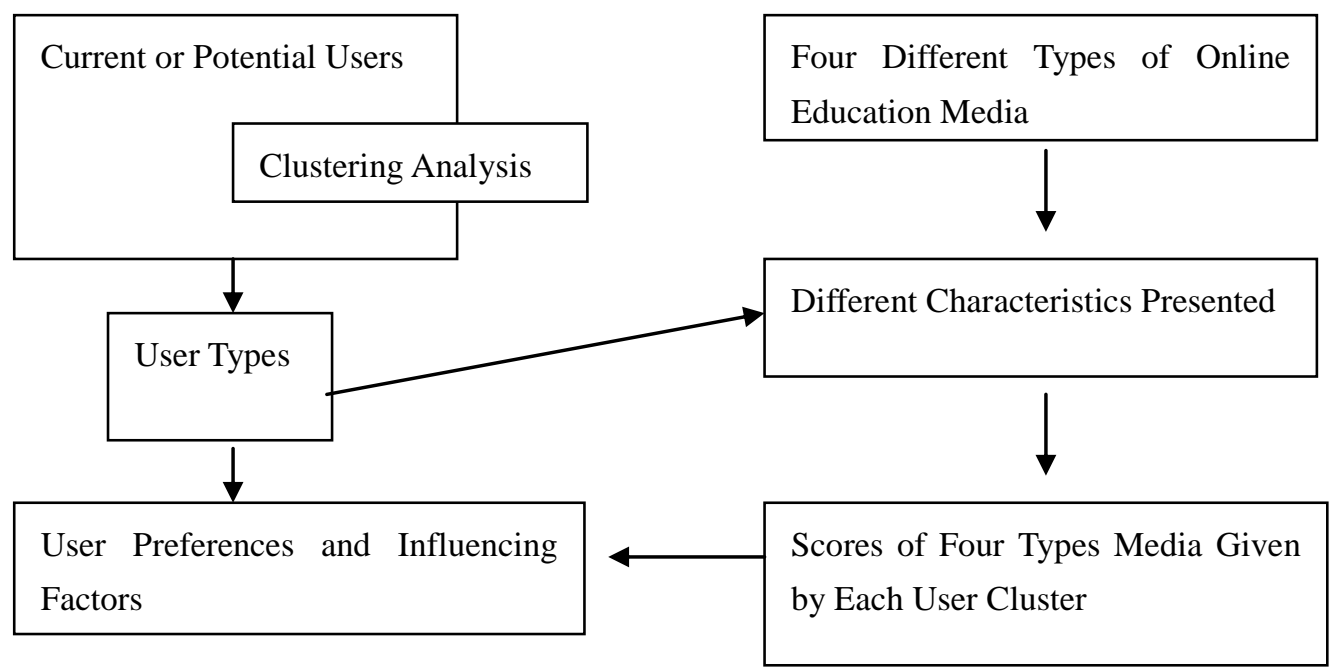

Figure 1. The Research Framework 


\section{The Research Procedure and Related Discussions}

\subsection{Step 1: Defining the Variables}

We collect data on users' characteristics through their answers to the questions designed. We define thirteen variables to describe their characteristics, which are summarized in Table 1.

Table 1. Variables and Their Meanings

\begin{tabular}{|c|c|}
\hline Variable Name & Description \\
\hline age & User's age \\
\hline occupation & Ranges from 1 to 8 to describe a job field \\
\hline$z-e d u c$ & $\begin{array}{l}\text { Z-Score of user's educational degree: under College }=1 ; \text { Bachelor }=2 ; \text { Graduate or above }=3 \text { : Z-Score }= \\
(\text { Value-1)/(3-1) }\end{array}$ \\
\hline major & Range from 1 To 9 , for 9 different major categories \\
\hline chmajor & User has a plan to change major $=1$; Otherwise $=0$ \\
\hline frapply & User has a plan to apply for education abroad $=1$; Otherwise $=0$ \\
\hline creditvl & User cares about whether the online courses offer certificate of accomplishment $=1$; Otherwise $=0$ \\
\hline flex & User can manage their own time to study at least half an hour everyday $=1$; Otherwise $=0$ \\
\hline follow & $\begin{array}{l}\text { User has habit of following the restricted timeline of courses }=1 \text {; User prefers choosing his/her own time of } \\
\text { studying }=0\end{array}$ \\
\hline ovteach & User prefers teacher teaching $=1$; User has no evident inclination of teacher teaching $=0$ \\
\hline ovsubset & User values systematic department setting over other factors in choosing platforms $=1$; User's attitude is neutral $=0$ \\
\hline overspec & User has big interest in certain area and has developed a habit of using certain related platforms $=1$; Otherwise $=0$ \\
\hline ovencyclo & User prefers gathering comprehensive knowledge to learning profoundly in a specific area $=1$; Otherwise $=0$ \\
\hline
\end{tabular}

The descriptive statistics based on the data collected back, which contains 128 effective sample points, exhibit some interesting results that are shown in Tables 2 and 3.

Table 2. (Question 6.) Do you have a plan to change your major? [Single-choice]

\begin{tabular}{lll}
\hline Options & Number & Percentage \\
\hline A. Yes & 41 & $32.03 \%$ \\
B. No & 87 & $67.97 \%$ \\
Number of effective sample points & 128 & $100 \%$ \\
\hline
\end{tabular}

Table 3. (Question 17.) Do you have a preference for a certain field and have you already developed a habit of using a specific platform related to this field? (Such as IT, Software Engineering, Business, Foreign Language, etc.) [Single-choice]

\begin{tabular}{lll}
\hline Options & Number & Percentage \\
\hline A. Yes & 34 & $26.56 \%$ \\
B. No & 94 & $73.44 \%$ \\
Number of effective sample points & 128 & $100 \%$ \\
\hline
\end{tabular}

As these results indicate, compared with the opposite side, the number of people who want to change their majors and have certain preferences for platforms concerning specific areas tends to be relatively small. Given the fact that including variables like occupation (which could be quite different from the user's original major), major (which may not be as influencing as we have expected because we have seen that people having no apparent inclinations towards specific areas account for the majority of the whole sample), chmajor (which could also be interruptive given that only few people want to change their majors), ovspec (which has been proved to be unimportant in choosing platforms) would possibly drag down the quality of our cluster analysis by raising more problems than they could solve, we opt to remove these four variables, leaving only the remaining nine as our clustering base.

\subsection{Step 2: Two-step Clustering of the Users}

As the variables consist of both continuous and discrete variables, frequently used methods such as K-means clustering 
may not be appropriate for processing the dataset. Therefore, we adopt a two-step clustering method, which is widely seen as supportive in analyzing mixed random variables. The users (respondents) are divided into four groups whose proportions are depicted by in Figures 2 and 3.

The defining characteristics of the four groups are listed as follows based on their influencing power.

Characteristics (ordered from the most to the least important) of Cluster 3 (accounting for $32.8 \%$, which has the biggest size):

A. Prefer acquiring comprehensive knowledge to learning profoundly in a specific area.

B. Value systematic department setting over other factors in choosing platforms.

C. Able to manage personal time to study at least half an hour daily.

D. Have the habit of following restricted timelines of courses.

E. Plan to apply for education abroad.

F. Prefer to be taught by teachers.

G. Value the certificate of accomplishment.

H. Have an education level below the average, which is 0.63 ( 0.5 means bachelor degree).

I. With an average age of 22.38 (the youngest group)

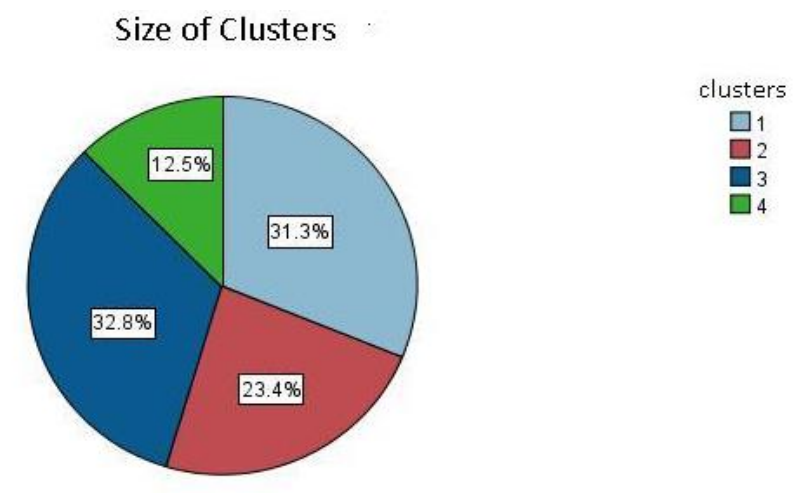

\begin{tabular}{|c|l|}
\hline Minimum Size & $16(12.5 \%)$ \\
\hline Maximum Size & $42(32.8 \%)$ \\
\hline Max/Min & 2.62 \\
\hline
\end{tabular}

Figure 2. Relative Sizes of the Four Clusters in Percentages

Characteristics (ordered from the most to the least important) of Cluster 1 (Accounting for $31.2 \%$, which is the second largest):

A. Prefer acquiring comprehensive knowledge to learning profoundly in a specific area.

B. Neutral attitude towards systematic department setting.

C. Cannot manage personal time to assure half an hour's study daily.

D. Have a habit of following the restricted timelines of courses.

E. Have no plans for applying for education abroad.

F. Prefer to be taught by teachers.

G. Value the certificate of accomplishment.

H. Have an education level hovering around the mean, which is 0.63 ( 0.5 means bachelor degree).

I. With an average age of 23.32 (the second oldest)

Characteristics (ordered from the most to the least important) of Cluster 2 (Accounting for $23.4 \%$, which is at the third place):

A. Prefer acquiring comprehensive knowledge to learning profoundly in a specific area.

B. Value systematic department setting over other factors in choosing platforms. 
C. Able to manage personal time to study at least half an hour daily.

D. Prefer choosing own personal time for studying.

E. Have no plans for applying for education abroad.

F. Prefer to be taught by teachers.

G. Value the certificate of accomplishment.

H. Have an education level above the average, which is 0.63 ( 0.5 means bachelor degree).

I. With an average age of 24.30 (the eldest)

\section{Clusters}

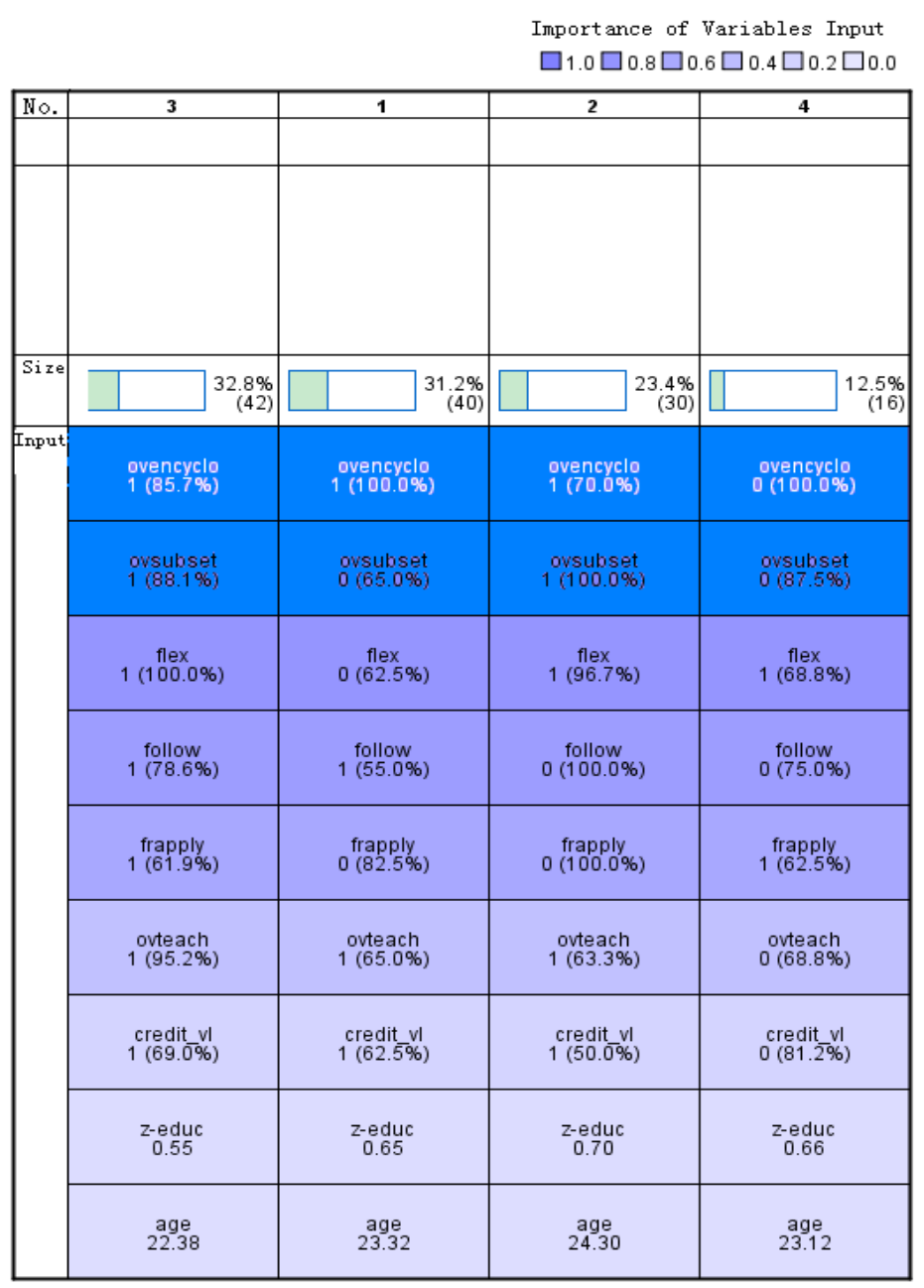

Figure 3. The Result of Clustering

Characteristics (ordered from the most to the least important) of Cluster 4 (Accounting for $12.5 \%$, which is the smallest):

A. Have no evident inclination in learning comprehensive knowledge compared with choosing one specific area.

B. Neutral attitude towards systematic department setting.

C. Able to manage personal time to study at least half an hour daily.

D. Prefer choosing own personal time for studying.

E. Plan to apply for education abroad.

F. Have no evident inclination of being taught by teacher.

G. Do not value the certificate of accomplishment over other factors.

H. Have an education level hovering around the average, which is 0.63 ( 0.5 means bachelor degree).

I. With an average age of 23.12 (the second youngest).

\subsection{Step 3: Analyzing the Preferences of the Clusters}

Four types of internet-based education platforms are chosen and their relative characteristics are summarized below: 
Table 4. A Detailed Description of the Four Types of Internet-Based Education Media

\begin{tabular}{|c|c|c|c|c|}
\hline Types & $\begin{array}{l}\text { Open online } \\
\text { courses }\end{array}$ & $\begin{array}{l}\text { Multi-major mutual support } \\
\text { /Resource sharing community }\end{array}$ & Single-field forum & Cloud platform \\
\hline Representative & MOOC & One-man University & $\begin{array}{l}\text { The IT Home, Excel } \\
\text { Home, Put club, etc. }\end{array}$ & Aedu.cn ${ }^{1}$ \\
\hline Special models & $\begin{array}{l}\text { Micro } \\
\text { Courses }^{2}\end{array}$ & & $\begin{array}{l}\text { Open Source } \\
\text { Community }^{3}\end{array}$ & \\
\hline $\begin{array}{l}\text { Courses are mainly } \\
\text { taught by teachers }\end{array}$ & Yes & Basically no & Basically no & $\begin{array}{l}\text { To some extent but } \\
\text { not a key feature }\end{array}$ \\
\hline Source of courses & $\begin{array}{l}\text { Mainly open } \\
\text { courses }\end{array}$ & Mainly videos ${ }^{5}$ & Various sources $^{6}$ & Mainly videos ${ }^{7}$ \\
\hline Fields covered & Broad & Broad & $\begin{array}{l}\text { Focuses on a specific } \\
\text { field }^{8}\end{array}$ & Specific Courses ${ }^{9}$ \\
\hline Clear department setting ${ }^{10}$ & No & Yes & No & No \\
\hline Giving credits & Yes & No & No & No \\
\hline $\begin{array}{l}\text { Restricted timelines } \\
\text { of teaching schedule }\end{array}$ & Yes $^{11}$ & No & No & No \\
\hline Group tasks and final examinations & Yes $^{12}$ & Some but not mandatory & No & $\begin{array}{l}\text { Some, but not } \\
\text { mandatory }\end{array}$ \\
\hline $\begin{array}{l}\text { Acknowledged by world renowned } \\
\text { universities }\end{array}$ & Yes $^{13}$ & Currently No & No & No \\
\hline Popularity worldwide & High & Low & Low & Low \\
\hline $\begin{array}{l}\text { Serve well in assisting application } \\
\text { for foreign education }\end{array}$ & Yes & Depends & Depends & Basically No \\
\hline $\begin{array}{l}\text { Availability of certificates of } \\
\text { accomplishment }\end{array}$ & Yes & No & No & No \\
\hline $\begin{array}{l}\text { Affiliated forum and resource } \\
\text { sharing platform }\end{array}$ & Yes & Yes & Yes & Yes \\
\hline Freedom of expression & High & High & High & Relatively low \\
\hline Offline supporting communities & Few & Many & No & No \\
\hline $\begin{array}{l}\text { Contribution of students' } \\
\text { spontaneous uploading and sharing }\end{array}$ & $\begin{array}{l}\text { Less } \\
\text { important }\end{array}$ & Crucial & Crucial & Not important \\
\hline
\end{tabular}

Users are asked to attach scores that are allowed to range from 1 to 10 to each type of online education media based on the comparison of the characteristics given above. We obtain the final result by screening the answers of each cluster and calculating the mean score for each of the four online education platforms. The type getting the highest score is identified as the cluster's strongest preference. We then compare the characteristics of their first choice (presented above) with reasons why they make such a choice (given by the respondents), which could be collected with the final question in the questionnaire:

\footnotetext{
${ }^{1}$ It aims at forming a platform to support efficient communication between school, parents and students. It is basically the extended version of traditional schools based on the Internet.

2 The duration ranges from five minutes to half an hour, mainly depending on spreading through mobilized media such as cell-phones.

${ }^{3}$ It concentrates on sharing resources and exchanging views in developing/using open source software. It is highly personalized

4 These are mainly provided by world-renowned universities.

5 They are recorded by the initiator and talents in specific fields (most of whom are top university students abroad).

6 The courses provided can be quite flexible, depending on the resources uploaded by members.

7 They are recorded by teachers of elementary/high schools aiming at assisting students in taking the standardized national examinations

${ }^{8}$ Examples of these fields include IT/Business/Foreign Languages.

9 The courses mainly aim at assisting students in preparing standardized examinations

${ }^{10}$ Complete sets of reference books recommended are also available.

${ }^{11}$ Late submissions of assignments after the deadline are deemed invalid toward getting the certificate.

12 Failing the final exam means no certificate granted.

13 More and more universities start to acknowledge the MOOC credits.
} 
Table 5. (Question 21.) The reason for choosing X (which could be any one of the four types) as your top choice is that: [Multiple-choice]

\begin{tabular}{|c|c|c|c|}
\hline & Options & Number & Percentage \\
\hline (1) & $\begin{array}{l}\text { Widely acknowledged by foreign universities and helpful in applying } \\
\text { for education abroad }\end{array}$ & 55 & $42.97 \%$ \\
\hline (2) & $\begin{array}{l}\text { Offers a certificate of accomplishment, which may serve well in } \\
\text { achieving specific goals (such as for an application /changing majors) }\end{array}$ & 51 & $39.84 \%$ \\
\hline (3) & $\begin{array}{l}\text { Has strict rules in setting schedules and deadlines for submitting } \\
\text { homework and is taught by teachers. }\end{array}$ & 50 & $39.06 \%$ \\
\hline (4) & $\begin{array}{l}\text { Has systematic department setting for each major and a whole set of } \\
\text { textbooks recommended }\end{array}$ & 47 & $36.72 \%$ \\
\hline (5) & $\begin{array}{l}\text { Comprehensive enough in covering knowledge of multi-fields which } \\
\text { can help expand views and accumulate knowledge }\end{array}$ & 68 & $53.13 \%$ \\
\hline (6) & $\begin{array}{l}\text { Minimal limitations on study time, which suits me who has } \\
\text { difficulties managing personal time }\end{array}$ & 30 & $23.44 \%$ \\
\hline (7) & $\begin{array}{l}\text { I am used to learning using mobilized tools and taking advantage of } \\
\text { fragmental time: the micro courses set by MOOC really suit me }\end{array}$ & 37 & $28.91 \%$ \\
\hline (8) & $\begin{array}{l}\text { I have a preference for certain fields so that I am inclined to use } \\
\text { certain forums related to those fields }\end{array}$ & 20 & $15.63 \%$ \\
\hline (9) & $\begin{array}{l}\text { I have developed a habit of using a certain platform, which is hard to } \\
\text { change }\end{array}$ & 7 & $5.47 \%$ \\
\hline & Number of effective sample points & 128 & \\
\hline
\end{tabular}

\section{The Final Results and Related Discussions}

The final results of our comparative analysis are presented below.

Table 6. The Mean Scores of the Platform Types Given by Different Clusters

\begin{tabular}{ccccc}
\hline Cluster & Open online courses & Multi-major mutual support /Resource sharing community & Single-field forum & Cloud platform \\
\hline 1 & 8.125 & 6.625 & 6.75 & 6.125 \\
2 & 8 & 9 & 7.5 & 5 \\
3 & 7.810 & 7.667 & 7.5 & 5.5 \\
4 & 6 & 6.25 & 7.5 & 5.5 \\
\hline
\end{tabular}

A. The mean scores of the platform types given by users of Cluster 1 :

As is clearly demonstrated above, users of Cluster 1 have a significant preference for using open online courses, which can be represented by MOOC. According to their answers to question 21, which indicate the reasons why they make such a choice, we can see that the primary influencing factors can be stated as the following: (ordered by the times of choosing)

a. Comprehensive enough in covering knowledge of multi-fields which can help expand views and accumulate knowledge;

b. Offers a certificate of accomplishment, which may serve well in achieving specific goals;

c. Has strict rules in setting schedules and deadlines for submitting homework and is taught by teachers;

d. Be used to learning using mobilized tools and taking advantage of fragmental time, and value the micro courses set by MOOC.

We see that preferring comprehensive knowledge serves as the most prominent feature of Cluster 1. Users in Cluster 1 also value certificates for specific reasons other than foreign education application because cluster 1 mainly consists of people who have no plans for studying abroad. They tend to like the MOOC type more simply because of its self-discipline mechanisms and assured teachers-teaching. Another important point that should be noted is that they have developed a habit of studying based on fragmental time and they tend to like micro-courses, which is a special way of the MOOC type. 
B. The mean scores of the platform types given by users of Cluster 2:

Statistics show that the choice of multi-major mutual support/resource sharing communities, which can be represented by the "one-man university", is mostly valued by users of Cluster 2 . The main reasons can be listed below:

a. Comprehensive enough in covering knowledge of multi-fields which can help expand views and accumulate knowledge;

b. Has systematic department setting for each major and a whole set of textbooks recommended;

c. Minimal limitations on study time to allow for a flexible schedule for studying.

Cluster 2 has an apparent preference toward the one-man university type. Combined with their characteristics, we may conclude that this is because they value systematic department setting more than any other factors in choosing a platform, which could only be offered by the one-man type. They have no demands of applying for foreign education, which means certificates and fame of the platform are not necessary. Regardless of their personal interest in certificates and teachers-teaching (which simply appears to be a relatively less important personal characteristic presented by the order above), their preferences for the one-man university type over MOOC can be taken as plausible. Also, they are inclined to manage their time of studying on a flexible basis but unfortunately MOOC stands at the very opposite side. These people have an inclination of learning comprehensive knowledge, which may (partly) explain why they value MOOC more than the single-field forum.

C. The mean scores of the platform types given by users of Cluster 3:

As shown above, users of cluster 3 value the MOOC type over other types of platforms, but the mean score of MOOC is fairly close to that of the one-man university type, being only about 0.2 points higher. The reasons given by them are listed as follows:

a. Comprehensive enough in covering knowledge of multi-fields which can help expand views and accumulate knowledge;

b. Widely acknowledged by foreign universities and helpful in applying for education abroad;

c. Offers a certificate of accomplishment, which may serve well in achieving specific goals;

d. Has strict rules in setting schedules and deadlines for submitting homework and is taught by teachers;

e. Has systematic department setting for each major and a whole set of textbooks recommended.

We may conclude from the descriptive information of Cluster 3 that these people have certain needs such as applying for education abroad, etc. They are more inclined to be attracted by comprehensive knowledge, which is not uncommon among potential international students who always possess a feature of broad interests and high curiosities. Although these people value systematic department setting over other factors, their needs of (for example) going abroad may very likely dominate their personal interests. That is, they have to choose the MOOC type because of its wider acknowledgement among foreign universities as well as a certificate, which will presumably play a crucial role in supporting their application. These users also value the mechanism of self-discipline, cross-supervision and the assured education quality provided by the MOOC type, all of which tend to serve their application fairly well. Therefore, we are not surprised at their first choice.

D. The mean scores of the platform types given by users of Cluster 4:

The figures indicate that users of Cluster 4 seem more inclined to using the single-field forum rather than any other media. The reasons given by them turn out to be the following:

a. Minimal limitations on study time to allow for a flexible schedule for studying;

b. Preference for a certain field so that the user is inclined to use certain forums related to that field;

c. A habit of using a certain platform, which is hard to change.

Combined with the characteristics of Cluster 4 described earlier, we find that these people have no apparent inclination towards many things, such as comprehensive knowledge, teachers-teaching and certificate of accomplishment, etc. They also have a neutral attitude towards systematic department setting. As a matter of fact, we spot that all mean scores given by these people tend to be lower than other clusters, which may probably indicate a more carefree and indifferent attitude of theirs towards the media features. It seems that they overvalue the freedom of managing personal time rather than the media type features, as we may see from the descriptions presented above about Cluster 4, they tend to choose their own time of studying and they also have the ability to manage their personal time. The reasons given by them show a match with our analysis and give further information showing their specific preferences for some certain fields. They may have developed a habit of using platforms of special areas, which is hard to change. These users, who have certain personal interests and have no need of applying for foreign education, are more likely to be IT programmers or engineering zealots. This conjecture is supported by the occupation information given by Cluster 4 . 


\section{Conclusion}

In this paper, we apply a two-step clustering analysis to sort our respondents (seen as current and potential users of internet-based education media) into four clusters, based on which we ultimately figure out the preferences of each cluster for four different types of internet-based education platforms (respectively) currently being widely used in China. The main conclusion we have reached has great implications for strategic planning over developing new forms of internet-based education means and improving the existing means.

Through our comparative analysis, we can conclude that factors such as the certificate and acknowledgement are key factors in affecting the choices of people who have special needs like going abroad or changing their majors while factors such as department setting and teachers-teaching can be of great value for people who accentuate education quality. It should be noted that the factors we have discussed here should always be studied together with people's habits concerning the management of their studying time, e.g. whether they have flexible time or not or whether they are willing to follow rules in terms of timelines.

A minor issue we would like to mention in passing before we end this paper is about the lower preferences shown by all the clusters for the last type of media -- the cloud platform. Our conjecture of the possible reason is that this platform only serves as an online extension of traditional schools, at least judged from its current way of management. This implies that it actually has low involvement with the internet spirit such as freedom, students' initiative, and resource-sharing with no boundaries. Still, the cloud platform is more likely to be dominated by teachers, often failing to provide students with adequate involvement. Such an online platform should have a long way to go in terms of bringing in the real internet spirit before it can be regarded as an effective means of internet-based education.

\section{Acknowledgements}

The authors thank the anonymous reviewers and the editors of the Journal for their helpful comments and suggestions.

\section{References}

Bates, A. W. (2003). Technology, Distributed Learning, and Distance Education. London: Rutledge.

Brown, L., Murphy, E., \& Wade, V. (2006). Corporate eLearning: Human Resource Development Implications for Large and Small Organizations. Human Resource Development International, 9(3), 415-427. http:/dx.doi.org/10.1080/13678860600893607

Chen, S. (2007). The Features and Trends of University Development in Australia and China. Higher Education Policy, 20(2), 207-216. http://dx.doi.org/10.1057/palgrave.hep.8300147

Chen, X., \& Wang, D. (2013). Analysis of Development of MOOC and Its Key Features. Modern Educational Technology, 11(23), 5-10.

Colwell, R. R. (2001). Closing the Circle of Information Technology. Communications of the ACM, 44(3), 31-32. http://dx.doi.org/10.1145/365181.365183

Dykman, C. A., \& Davis, C. K. (2008). The Shift Toward Online Education. Journal of Information Systems Education, 19(1), 11-16.

Jacob, J., \& Szirmai, A. (2007). International Knowledge Spillovers to Developing Countries: The Case of Indonesia. Review of Development Economics, 11(3), 550-565. http://dx.doi.org/10.1111/j.1467-9361.2007.00360.x

Liu, Y., Wang, X., Liu, B., \& Zhong, B. (2005). A Cluster-Based Approach on Mining Text Preference. The Research on Computer Application, 12, 21-23.

Lu, J. (2012). Application of K-means Algorithm in Customer Relation Management in Telecommunicating Industry. Fujian Computer, 8, 83-84.

Moore, M. G., \& Anderson, W. G. (Eds.) (2003). Handbook of Distance Education. Mahwah, NJ: Lawrence Erlbaum Associates.

Starke-Meyerring, D., \& Andrews, D. (2006). Building a Shared Virtual Learning Culture. Business Communication Quarterly, 69(1), 25-49. http://dx.doi.org/10.1177/1080569905285543

Tilak, J. (2007). Post-Elementary Education, Poverty, and Development in India. International Journal of Educational Development, 27(4), 435-445. http://dx.doi.org/10.1016/j.ijedudev.2006.09.018

Wang, Y., Zhang, J., \& Zhang, B. (2013). Analysis of Typical MOOC Programs and Its Enlightenment. Journal of Distance Education, 4, 69-75.

\section{(cc) BY}

This work is licensed under a Creative Commons Attribution 3.0 License. 